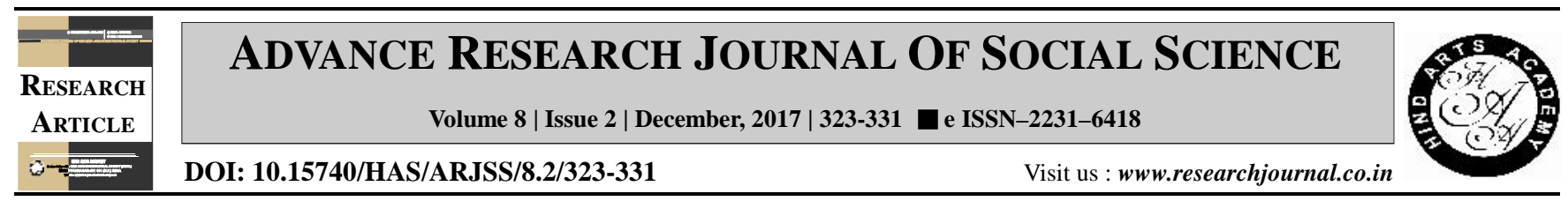

\title{
A study to find the safety practices of mothers for prevention of unintentional injuries among 4-6 year children
}

Preeti Verma* and Garima Babel ${ }^{1}$

Govt. Meera Girls College, UDAIPUR (RAJASTHAN) INDIA

'Bhupal Nobles' University, UDAIPUR (RAJASTHAN) INDIA

(Email: darshan.verma9@gmail.com; mayankgarima@gmail.com)

\section{ARTICLE INFO :}

$\begin{array}{lll}\text { Received } & : & 21.06 .2017 \\ \text { Revised } & : & 01.11 .2017 \\ \text { Accepted } & : & 15.11 .2017\end{array}$

\section{KEY WORDS :}

Unintentional injuries, Safety

practices, Communication strategies

\section{HOW TO CITE THIS ARTICLE :}

Verma, Preeti and Babel, Garima (2017). A study to find the safety practices of mothers for prevention of unintentional injuries among 4-6 year children. $A d v$. Res. J. Soc. Sci., 8 (2) : 323-331, DOI: 10.15740/HAS/ARJSS/8.2/323-331.

*Author for correspondence

\begin{abstract}
Specific directed efforts are required to study the problem and develop suitable communication strategies to retract the unintentional injuries in children as globally, injuries have turn out to be the universal and foremost cause of death among the children (WHO, 2012) and simultaneously it is a neglected epidemic in India (Jagnoor, et al., 2012). Accordingly, 180 mothers of Udaipur (Rajasthan) were selected through a stratified purposive sampling technique using a self designed questionnaire to elicit response regarding the safety practices of mothers regarding the three prevalent unintentional injuries i.e. Burns, Scalds and Electrocution, Poisoning and Drowning among children of 4-6 year age. From the study results, it can be divulged that despite the reality that Burns, Scalds and Electrocution and Poisoning were alarming, less than half (40.6\% and $44.2 \%$ ) of the mothers did not realized the importance of following the safety measures relevant to these two injuries but mothers did added efforts to prevent Drowning as $61.9 \%$ were following the safe practices regarding this injury. These set of findings facilitated in formulating innovative and targeted communication strategies so that, a few key steps can be taken forward by the mothers in the battle to trim down injuries from the blooming lives each day.
\end{abstract}

